Revistade
Economild
Contemporâned

\title{
A INTERNACIONALIZAÇÃO DAS EMPRESAS SUL-COREANAS E O PAPEL DO ESTADO
}

\author{
Lídia Ruppert ${ }^{a}$ \\ Mario Augusto Bertella ${ }^{b}$
}

\begin{abstract}
${ }^{a}$ Doutora em Economia pelo Instituto de Economia da Universidade Estadual de Campinas (IE/Unicamp) e pesquisadora colaboradora do Núcleo de Economia Industrial e da Tecnologia (NEIT) do IE/Unicamp.

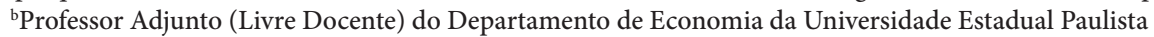

(Unesp).
\end{abstract}

Artigo recebido em 27/04/2016 e aceito para publicação em 13/03/2018.

RESUMO: Este artigo tem como objetivo apresentar o processo de internacionalização (tardio) das empresas coreanas ocorrido entre os anos de 1990 e 2015, seus determinantes e o grau de envolvimento do Estado nesse processo. Entre os fatores determinantes do investimento direto externo coreano, destacam-se, entre outros: mão de obra barata, mercado doméstico saturado, desvantagens de custos, concorrência e a nítida estratégia governamental em transformar a Coreia do Sul numa potência regional. Conclui-se que a internacionalização das empresas coreanas não foi resultado das forças livres de mercado. Houve a percepção por parte do governo de que esse processo seria não apenas relevante como também necessário para a inserção virtuosa da Coreia do Sul nas estruturas produtivas e comerciais internacionais.

PALAVRAS-CHAVE: Coreia do Sul; investimento direto externo; internacionalização.

\section{CLASSIFICAÇÃO JEL: F23.}




\title{
THE INTERNATIONALIZATION OF SOUTH KOREAN COMPANIES AND THE ROLE OF THE STATE
}

\begin{abstract}
The purpose of this article is to present the process of (late) internationalization of Korean companies occurred between the years of 1990 and 2015, its determinants and the degree of involvement of the State in this process. We can point out some determinants in this process, such as: cheap labor, problematic domestic market, cost disadvantages, competition and a clear public strategy to turn South Korea into a regional power. We conclude that this process was not a result of free market forces. There was a perception by the government that this process would not only be relevant but also necessary for the virtuous integration of South Korea in the international trade and productive structures.
\end{abstract}

KEYWORDS: South Korea; foreign direct investment; internationalization. 


\section{INTRODUÇÃO}

Há décadas, as empresas dos países desenvolvidos têm se internacionalizado via investimento direto externo (IDE). Contudo, somente nos anos 1980 e, especialmente na década de 1990, as empresas multinacionais (EMN) dos países em desenvolvimento começaram, de fato, a se aventurar fora de seu país de origem. Mesmo que tardiamente, diversos deles, principalmente os newly industrialized contries (NIC) asiáticos ${ }^{1}$, emergiram como grandes fontes mundiais de IDE. Nos últimos 20 anos, os afluxos de investimento direto externo advindos da Coreia aumentaram significativamente. Essas inversões concentraram-se no setor manufatureiro e, em menor grau, no setor de comércio.

A partir dos anos de 1990, uma série de desregulamentações e flexibilização do won coreano em relação ao dólar foram feitas para que os chaebols pudessem concorrer nos mercados globais em condições mais favoráveis, dado o amplo movimento de globalização financeira que ocorria no mundo capitalista (INFOMAG, 2010).

Em 2005, o governo anunciou o Plano de Ativação de Investimentos Externos a fim de reforçar a expansão internacional das companhias nacionais. Desde então, diversos outros instrumentos e medidas têm sido utilizados para intensificar a saída de IDE da Coreia com o objetivo de fortalecer a competitividade internacional das empresas coreanas, como, por exemplo, apoio financeiro, estímulos fiscais, garantias de investimento e assistências com assuntos administrativos e técnicos (INFOMAG, 2010; KIM e RHE, 2009).

Note-se que o estudo da internacionalização das empresas sul-coreanas é um caso especial não só porque se trata de um país em desenvolvimento, mas também porque o Estado comandou fortemente não apenas os processos de industrialização e criação dos ativos intangíveis, como também a internacionalização de suas empresas.

Este artigo tem como objetivo apresentar o processo de internacionalização das empresas coreanas entre os anos 1990 e 2015, seus determinantes e o grau de envolvimento do Estado nesse processo. Além dessa introdução, este estudo conta com três seções e uma breve conclusão. Na primeira, será feito o mapeamento da evolução das inversões coreanas segundo o volume de fluxos e estoques, regiões e principais destinos e setores de concentração. Na seção seguinte serão discutidos o processo de internacionalização das grandes empresas coreanas via IDE e seus determinantes. Em um terceiro momento apresentamos as diversas medidas públicas de incentivo às inversões coreanas. Os comentários finais fecharão este trabalho.

1 Coreia do Sul, Cingapura, Hong Kong e Taiwan. 


\section{O INVESTIMENTO DIRETO EXTERNO COREANO: UM PANORAMA GERAL}

Os afluxos de investimento direto externo da Coreia se iniciaram a partir da década de 1980. Entretanto, as firmas somente engajaram-se ativamente nesse movimento a partir de 1990, ano no qual as saídas de IDE excederam as entradas pela primeira vez no país e a Coreia passou a ser um dos maiores investidores na Ásia (YOON, 2007).

De lá para cá, segundo dados da UNCTAD (2017), o estoque de IDE no resto do mundo de empresas coreanas aumentou cerca de nove vezes, passando de US\$ 3,6 bilhões em 1990 para mais de US\$ 31 bilhões em 2016 (Gráfico 1). Já o afluxo de IDE coreano aumentou de US\$ 1 bilhão em 1990 para cerca de US\$ 27 bilhões em 2016 (Gráfico 2). Como percentagem do PIB, o estoque de IDE no exterior passou de $0,8 \%$ para $22 \%$ nos mesmos anos.

\section{Gráfico 1 - Estoque de IDE coreano no resto do mundo (em milhões de dólares)}

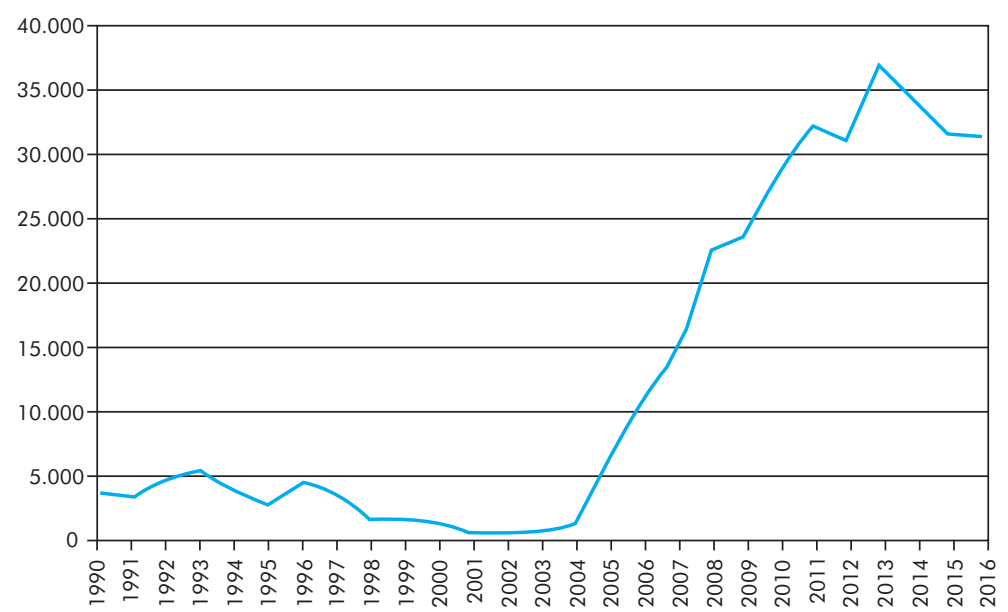

Fonte: Elaboração própria com base em dados de UNCTAD (2017).

A tendência de investidor externo líquido que se configurava ao longo dos anos 1990 foi revertida com a crise de 1997. Enquanto o país drenava seus investimentos externos, a abrupta desvalorização da moeda coreana e a queda dos preços (inclusive salários) atraiu o fluxo de IDE do mundo. Uma vez recuperada do choque, a partir de 2002 a Coreia retomou a saída de investimento direto externo (YOON, 2007). Esse movimento intensificou-se a partir de 2005 e, associado à queda dos influxos de IDE que vinha ocorrendo desde 2004, permitiu que o país retomasse a posição de investidora externa líquida, na qual se mantém até hoje. 
Gráfico 2 - Afluxo de IDE coreano, 1990-2016 (em milhões de US\$)

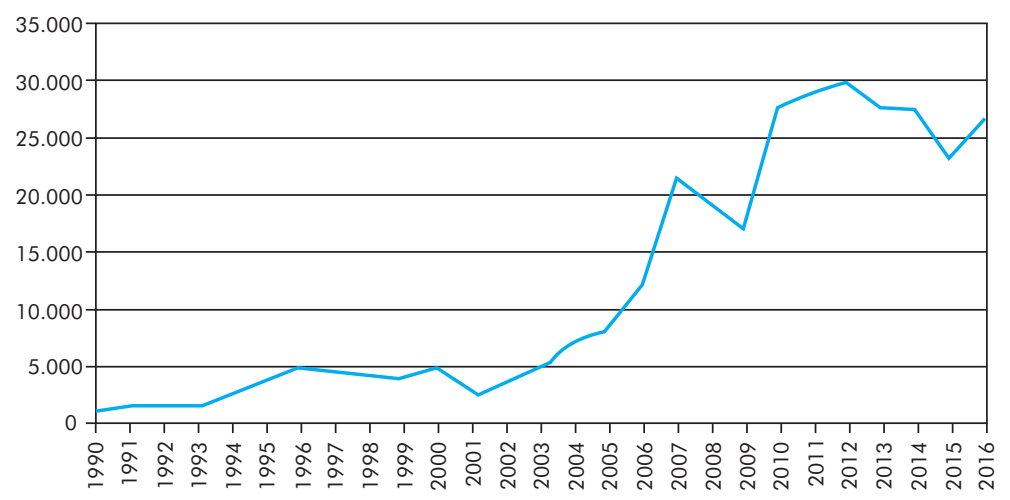

Fonte: Elaboração própria com base em dados de UNCTAD (2017).

Essa elevação foi guiada principalmente por investimentos destinados ao desenvolvimento de recursos no exterior. Devido ao grande aumento dos preços do petróleo, as empresas coreanas utilizaram a internacionalização via IDE como estratégia global de administração para ampliar o acesso a mercados (YOON, 2007).

Em todo o período, a Ásia representou o espaço geográfico de maior investimento coreano, seguido pela América do Norte com as mesmas oscilações para mais ou para menos na sequência de anos (Gráfico 3). A América Latina e a Europa também receberam investimentos várias vezes superiores às suas tendências históricas em função de fusões e aquisições.

\section{Gráfico 3 - IDE coreano no mundo, por região (em \%)}

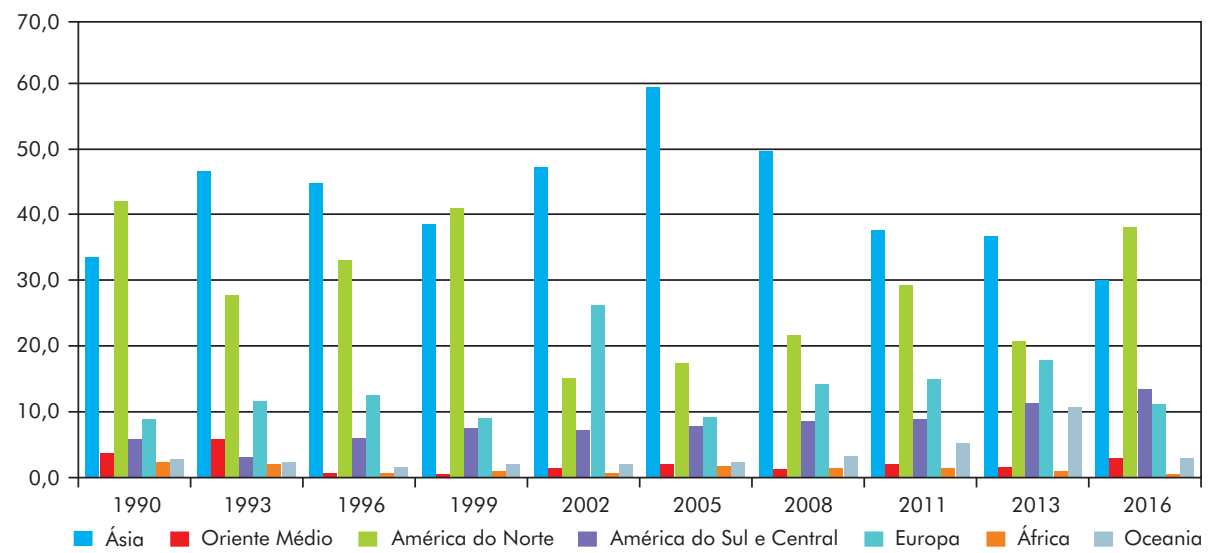


Ao longo dos anos 1990, a Ásia foi a região que mais se destacou como receptora dos investimentos coreanos, embora tenha apresentado tendência à queda ao longo da segunda metade da década, em função da crise asiática, ao mesmo tempo que a América do Norte ganhou importante destaque. Entre 1990 e 1995, a participação da Ásia passou de $34 \%$ do IDE coreano total para 55\%. Já em 2000, a parcela caiu para $31,7 \%$. A participação da América do Norte, para os mesmos anos, foi de 43\%, 18\% e 28,2\% (dados de Korea Eximbank).

Entre 2000 e 2005, a Ásia recuperou sua condição de destino dominante e chegou a representar quase $60 \%$ dos investimentos coreanos, em detrimento da participação da América do Norte. Entretanto tal tendência reverteu-se severamente nos dez anos seguintes. Em 2016, a Ásia concentrou apenas 30,2\% das inversões, ao passo que a América do Norte conquistou 38,6\%. Esse direcionamento maior dos investimentos coreanos para os países da América do Norte sugerem maior desenvolvimento e capacidade competitiva internacional das empresas coreanas e maior procura por ativos estratégicos nos países avançados.

Ganhou destaque também nesse período a Europa, que passou de 9,4\% em 2005 para 11,2\% em 2016. A América Latina, por sua vez, demonstrou maior crescimento a partir de 2010, refletindo, em grande medida, a procura das empresas coreanas por recursos naturais e mercados internos.

Em relação aos países que mais receberam os fluxos de investimentos da Coreia, desde meados de 1990 destacam-se: China, EUA, Hong Kong e Vietnã (Quadro 1). Entre 1990 e 1995, a Indonésia era um dos principais destinos dos fluxos de investimento coreano, recebendo, em 1990, 17\% destes. Entretanto esse papel foi suplantado pela China, que, de $1,5 \%$ em 1990, passou a receber $26 \%$ do IDE da Coreia em 1995, enquanto a Indonésia recebeu apenas 6,5\%. Nos mesmos cinco anos, os EUA também perderam importância como receptores dos investimentos coreanos. De 33\% em 1990 passou a menos de 18\% em 1995. A partir desse ano, a Indonésia passou à condição marginal como receptora desses investimentos. Os dois principais destinos, desde então, têm sido a China e os EUA, trocando de posição entre eles de período em período, porém nunca sendo ultrapassados por um terceiro país. Entretanto é importante destacar a perda de participação que a China demonstrou entre 2000 e 2015, passando de $14,8 \%$ para 9,6\%, respectivamente. Muito desse movimento pode ser explicado pelo aumento dos salários no país nos últimos anos, impulsionando o deslocamento de corporações coreanas para outros países cujos custos produtivos sejam menores. No segundo escalão dos principais receptores de IDE coreano estão Vietnã e Hong Kong. 
Quadro 1 - IDE coreano no mundo: principais destinos (em \% do total)

\begin{tabular}{lccccccc}
\hline & $\mathbf{1 9 9 0}$ & $\mathbf{1 9 9 5}$ & $\mathbf{2 0 0 0}$ & $\mathbf{2 0 0 5}$ & $\mathbf{2 0 0 8}$ & $\mathbf{2 0 1 0}$ & $\mathbf{2 0 1 5}$ \\
\hline China & 1,5 & 26,0 & 14,0 & 40,0 & 17,0 & 14,8 & 9,6 \\
EUA & 33,0 & 17,7 & 27,0 & 18,0 & 22,0 & 13,9 & 22,6 \\
Hong Kong & 5,7 & 3,4 & 5,0 & 4,0 & 11,0 & 5,3 & 6,2 \\
Vietnã & - & 5,7 & 1,4 & 4,5 & 6,2 & 3,5 & 5,2 \\
Indonésia & 17,0 & 6,5 & 1,8 & 1,4 & 2,4 & 3,7 & 2,3 \\
\hline
\end{tabular}

Fonte: Elaboração própria com base em dados de Korea Eximbank Foreign Investment Statistics.

Não considerando os investimentos em paraísos fiscais, que absorvem mais da metade do total investido no continente latino-americano, Peru, Brasil e México, respectivamente, são os países que absorvem os maiores montantes de capital coreano na região. O Brasil, em especial, atraiu capitais produtivos coreanos em função do acordo de integração regional (Mercosul), de seu amplo e crescente mercado interno, de seus abundantes recursos naturais e da maior abertura e facilitação ao capital internacional. Em 2010, o país chegou a capturar 4,3\% do IDE coreano, caindo nos anos seguintes.

Faz-se primordial ressaltar que há importantes diferenças em termos de uso de fatores de produção entre os investimentos diretos externos que seguiram para os países desenvolvidos e os que foram direcionados aos países em desenvolvimento. Moon (2007) argumenta que, enquanto o IDE coreano realizado nos países desenvolvidos (especialmente EUA) foi concentrado em manufaturas intensivas em capital, sendo necessário maior uso de pesquisa e desenvolvimento, o IDE enviado às economias em desenvolvimento foi centrado nas indústrias intensivas em trabalho (sobretudos os países asiáticos, com grande destaque para a China) e em recursos naturais (América Latina e África). No caso das inversões destinadas aos países europeus, o autor destaca o objetivo de suplantar barreiras comerciais para atingir os mercados internos dessa região. Sendo assim, fica claro que as motivações que levaram à internacionalização das corporações coreanas dependeram das vantagens oferecidas pelos países hospedeiros.

O perfil do investimento coreano nos diversos setores tem apresentado importantes modificação de tendência. A despeito das oscilações, entre 1990 e 2005 o IDE foi predominantemente alocado no setor manufatureiro (Quadro 2). Com exceção de alguns poucos anos, a indústria de transformação concentrou mais de $40 \%$ das inversões coreanas, tendo chegado em 1996 a absorver 64\% do total. Entretanto, após a crise econômica internacional, o setor passou a perder participação sistematicamente, atingindo a parcela de 25,5\% em 2015. O comércio (atacado evarejo) foi a segunda atividade mais concentradora dos afluxos coreanos entre 1990 e 2008, tendo perdido importante participação após essa data. $\mathrm{O}$ extrativismo e a mineração, depois de quinze anos perdendo expressão em termos 
de recebimento do IDE da Coreia, a partir de 2006 passou a se destacar novamente, alcançando em 2010 a mesma participação que as manufaturas (cerca de 30\%). Nos anos seguintes houve perda de participação do setor, contudo, ainda em 2015 foi mais expressivo do que o comércio. Dois setores que praticamente não absorviam nenhum investimento advindo da Coreia até o ano 2000 têm se destacado no período pós-crise internacional: atividades imobiliárias e atividades financeiras e de seguro.

Quadro 2 - Coreia: IDE por setor de atividade (em \% do total)

\begin{tabular}{|c|c|c|c|c|c|c|c|c|c|c|c|c|c|c|}
\hline & 1990 & 1992 & 1994 & 1996 & 1998 & 2000 & 2002 & 2004 & 2006 & 2008 & 2010 & 2012 & 2014 & 2016 \\
\hline $\begin{array}{l}\text { Extrativismo } \\
\text { e Mineração }\end{array}$ & 14,2 & 11,0 & 5,0 & 5,5 & 2,4 & 1,8 & 5,3 & 5,0 & 12,5 & 16,0 & 30,6 & 27,3 & 21,1 & 11,3 \\
\hline Manufatura & 44,5 & 50,0 & 63,0 & 64,0 & 47,4 & 31,7 & 45,7 & 54,5 & 47,2 & 31,0 & 30,2 & 30,0 & 26,5 & 25,5 \\
\hline $\begin{array}{l}\text { Comércio } \\
\text { - Varejo e } \\
\text { atacado }\end{array}$ & 21,0 & 22,3 & 23,7 & 13,3 & 39,3 & 16,4 & 29,8 & 17,5 & 10,5 & 16,7 & 6,5 & 6,6 & 5,8 & 7,2 \\
\hline $\begin{array}{l}\text { Atividades } \\
\text { imobiliárias }\end{array}$ & 1,5 & 1,3 & 0,8 & 3,0 & 3,3 & 8,6 & 5,5 & 5,1 & 5,3 & 7,6 & 6,6 & 4,9 & 14,1 & 15,3 \\
\hline $\begin{array}{l}\text { Atividades } \\
\text { financeiras e } \\
\text { de seguro }\end{array}$ & - & - & - & - & - & 1,3 & 5,6 & 8,5 & 6,9 & 8,2 & 11,0 & 11,8 & 13,3 & 20,5 \\
\hline Outros & 18,8 & 15,4 & 7,5 & 14,2 & 7,6 & 40,2 & 8,1 & 9,4 & 17,6 & 20,5 & 26,1 & 24,3 & 33,3 & 40,7 \\
\hline
\end{tabular}

Fonte: Elaboração própria com base em dados de Korea Eximbank Foreign Investment Statistics.

Apesar da internacionalização tardia da Coreia, algumas de suas empresas estão presentes no ranking mundial elaborado pela UNCTAD das 100 empresas não financeiras transnacionais dos países em desenvolvimento com maior volume de ativos no exterior em 2014. São elas: Samsung Eletronics (4 lugar), Hyundai Motor Company $\left(13^{\circ}\right)$, Hanwha Corporation $\left(18^{\circ}\right)$, POSCO $\left(34^{\circ}\right)$, LG Eletronics $\left(81^{\circ}\right)$, Doosan Corp $\left(88^{\circ}\right)$ e SK Hynix Inc $\left(94^{\circ}\right)$.

Atualmente a maior empresa internacionalizada coreana, segundo a Unctad, é a Samsung Corporation. Nascida como uma pequena empresa de exportação em 1938, a empresa, também localizada no segmento de eletroeletrônicos, foi crescendo ao longo das décadas a partir de fusões e aquisições e transbordando para o restante do mundo, alcançando, além do $4^{\circ}$ lugar no ranking citado acima, a $47^{\mathrm{a}}$ posição do ranking da UNCTAD das 100 maiores ETN não financeiras mundiais. Em 2014, os ativos estrangeiros da corporação representavam $27 \%$ do total, as vendas no exterior $90 \%$ do total e $69 \%$ dos funcionários da empresa encontravam-se fora do país ${ }^{2}$.

\footnotetext{
2 Dados retirados do WIR 2016 - UNCTAD e do site oficial da empresa: http://www.samsung.com/us.
} 
Fundada em 1967 como uma empresa do conglomerado (chaebol) coreano Hyundai, a Hyundai Motor Company atualmente é a maior empresa automotiva da Coreia e uma das maiores em termos mundiais. O grupo alcançou escalas mundiais em 1999, quando comprou $51 \%$ de um dos maiores produtores de carros coreanos, a Kia Motors Corporation e, após 2001, ganhou independência do conglomerado. Entretanto, as companhias continuaram a operar separadamente e inclusive em concorrência uma com a outra. De acordo com o ranking da UNCTAD, a empresa possuía, em 2014, 21\% de seus ativos e $40 \%$ de seus empregados em terras estrangeiras. Em relação às vendas, $55 \%$ delas eram realizadas no exterior ${ }^{3}$.

Terceira maior ETN coreana, Hanwha Corporation foi fundada em 1952 como uma empresa fabricante de explosivos. Com o passar das décadas, a empresa foi diversificando suas áreas de atuação, incorporando os setores de máquinas, defesa e comércio. Segundo dados da UNCTAD, em 2014 a empresa concentrava no exterior $21 \%$ de seus ativos e de seus empregados, bem como $16 \%$ de suas vendas.

A empresa siderúrgica POSCO desponta como uma das maiores ETN coreanas. Nascida em 1967 como uma joint-venture com o governo coreano e uma multinacional privada, em 1997 o Estado passou a deter participação minoritária, sendo totalmente privatizada em 2000. Desde 1998 é uma das maiores produtoras mundiais de aço, com grande ampliação de suas bases produtivas no exterior (presença em 25 países). Em 2014, 22\% de seu ativos, 30\% das vendas e 16\% dos empregos encontravam-se no exterior.

A LG Corporation iniciou suas atividades na Coreia do Sul em 1947 já como um grupo 100\% privado. Atualmente seus negócios são operados por 147 subsidiárias distribuídas em 53 países, que empregam cerca de 177 mil empregados. Instalado nos cinco continentes, o conglomerado reúne 52 corporações. O Grupo LG atua em diversos segmentos, porém sua principal atividade concentra-se em equipamentos eletroeletrônicos. Segundo a UNCTAD (2016), o grupo LG possuía no exterior, em 2014, cerca de $22 \%$ dos seus ativos totais, $55 \%$ dos seus empregados e $75 \%$ do total das vendas eram feitas fora da Coreia ${ }^{4}$.

A Doosan Corp. é uma empresa com foco no apoio à infraestrutura, em especial no setor de maquinário pesado e construção. A mais antiga de todas foi criada em 1896. Apesar de diversas atuações no exterior em termos de comércio e produção, apenas nos últimos 10 anos a empresa tornou-se de fato uma verdadeira marca global.

\footnotetext{
3 Dados retirados do WIR 2009 - UNCTAD e do site oficial da empresa: http://www.hyundai.com.

4 Dados retirados do WIR 2009 - UNCTAD e do site oficial da empresa: http://www.lg.com/global.
} 
Em 2014, 23\% de seus ativos, 37\% de suas vendas e 40\% de seus empregados concentravam-se no exterior.

A sétima empresa transnacional coreana de maior destaque é a SK Hynix, cujas atividades concentram-se no setor de equipamentos eletroeletrônicos (semicondutores de memória), sendo atualmente a sexta maior fabricante mundial de chip de memória. A mais jovem das cinco maiores, a companhia foi fundada em 1983 com o nome de Hyundai Electronics, pertencendo também ao chaebol Hyundai. Em 1999 houve a fusão da empresa com a LG Semiconductor. Em 2001, tornou-se independente do conglomerado e seu nome foi alterado para Hynix Semiconductor. Em 2012 seu maior acionista passa a ser a SK Telecom, e seu nome é alterado para SK Hynix Inc. Em 2014, 23\% dos ativos da companhia encontravam-se no exterior, assim como 20\% dos seus empregados e as vendas no exterior representavam 93\% do total ${ }^{5}$.

Esse mapeamento das empresas coreanas mais internacionalizadas, segundo o volume de ativos no exterior (Quadro 3), demonstra que, apesar de as participações dos ativos e dos empregados no exterior em relação ao total não serem tão expressivas, as vendas realizadas fora da Coreia têm grande peso nas atividades totais das companhias. Também é importante destacar que as sete empresas coreanas mais internacionalizadas são todas integralmente privadas, o que evidencia uma liderança do setor privado no movimento de internacionalização da Coreia. Passemos, então, à discussão dos determinantes do IDE coreano.

Quadro 3 - Coreia: maiores empresas transnacionais (2014)

\begin{tabular}{lccc}
\hline & Ativos & Vendas & Empregados \\
\hline Samsung Eletronics & Exterior & Exterior & Exterior \\
Hyundai Motor Company & 27 & 90 & 69 \\
Hanwha Corporation & 21 & 55 & 40 \\
POSCO & 21 & 16 & 21 \\
LG Electronics Inc. & 22 & 30 & 16 \\
Doosan Corp. & 22 & 75 & 55 \\
SK Hynix Inc. & 23 & 37 & 40 \\
\hline
\end{tabular}

Fonte: UNCTAD (2016).

5 Dados retirados do WIR 2009 - UNCTAD e do site oficial da empresa: http://www.skhynix.com. 


\section{O PROCESSO DE INTERNACIONALIZAÇÃO DAS EMPRESAS COREANAS E SEUS DETERMINANTES}

Para explicar o processo de internacionalização das empresas coreanas é preciso voltar ao desenvolvimento da indústria na Coreia e ao surgimento dessas grandes corporações (chaebols). O governo de Park Chung Hee (1961-1979), identificando que era essencial a presença de uma indústria competitiva e exportadora para independência externa e desenvolvimento econômico do país, promoveu, de forma coordenada, uma série de políticas macroeconômicas (controle de preços, câmbio e crédito), comerciais (proteção do mercado doméstico por meio de tarifas de importações), financeiras (controle do mercado de capitais) e, especialmente, industriais para alcançar esse objetivo.

Em relação diretamente ao setor industrial, o governo estabeleceu, por meio dos planos quinquenais de desenvolvimento econômico, regras de entrada e saída nos setores priorizados pelo governo e ofereceu incentivos financeiros (acesso preferencial aos empréstimos estrangeiros) e fiscais aos chaebols que empreendessem o projeto de desenvolvimento (AMSDEN, 1987).

Durante a década de 1960, a indústria leve foi incentivada, promovendo industrialização por substituição de importações. Ademais, também foram priorizadas as indústrias de fertilizantes, cimento, produtos químicos e refinarias de petróleo. Houve também preocupação em assegurar o fornecimento de energia para o país por meio de hidrelétricas e termelétricas. Assim, um conjunto de grandes empresas nacionais foi se fortalecendo e se destacando no mercado internacional em cada segmento industrial protegido.

$\mathrm{Na}$ década seguinte houve a passagem da indústria leve para a indústria pesada. Os setores incentivados passaram a ser ferro e aço, máquinas e equipamentos, equipamentos de transporte, navios, petroquímica, automobilística, eletrônica e nuclear. Durante essas duas décadas o projeto desenvolvimentista foi financiado com poupança interna e empréstimos internacionais realizados diretamente pelo governo e transferidos aos chaebols por intermédio de bancos públicos. A preferência pelos empréstimos ao IDE foi em função de dois principais fatores, a saber: (i) o ambiente político coreano somado ao pequeno mercado consumidor interno não seria atrativo de IDE no volume necessário para fazer frente às necessidades coreanas; e (ii) a tomada direta de empréstimos permitia ao governo a alocação dos recursos da forma que desejasse, sem depender das estratégias próprias das EMN (LEE, 2011).

Nesse período a realização de IDE também era fortemente controlada e restringida pelo Estado, uma vez que este via a saída das empresas como mais uma pressão deficitária sobre o balanço de pagamentos e também como um risco ao projeto de industrialização do país. O IDE coreano era permitido apenas para os seguintes casos: (i) garantir o abastecimento e desenvolvimento de matéria-prima e insumos inexistentes no mercado 
interno; (ii) recuperar a competitividade internacional da empresa; (iii) remover gargalos; e (iv) promover as exportações da produção doméstica (LEE, 2011).

Já na década de 1980, devido ao início da mudança de orientação política (redemocratização) e econômica (liberalização) na Coreia do Sul, alguns incentivos aos chaebols foram retirados, bem como algumas restrições às indústrias que não eram relacionadas aos planos de desenvolvimento (AMSDEN, 1987). Contudo essas empresas já haviam ganhado capacidade tecnológica e humana para concorrer no mercado internacional com menores proteções, embora estivessem altamente endividadas. Por sua vez, o Estado foi essencial no redirecionamento da indústria coreana para a produção de bens intensivos em capital e tecnologia e para o fortalecimento do poder competitivo dos chaebols. As indústrias eletrônica, de automação industrial e de informação foram alvo dos planos de desenvolvimento dessa década, com pesados incentivos à capacitação humana, pesquisa e desenvolvimento nesse setor (RIBEIRO e RUPPERT, 2011). Ademais, não houve interrupção dos canais de crédito internacionais para a Coreia, no início da década de 1980, como ocorreu com a América Latina. A grande capacidade exportadora coreana fez com que os financiamentos externos continuassem para o país, o que permitiu reestruturação do passivo das empresas coreanas de forma mais suave e continuidade dos projetos de sofisticação da estrutura produtiva exportadora e de seus processos de internacionalização.

A partir do final dos anos 1980, os EUA, perdendo concorrência para as empresas coreanas, forçam a Coreia a valorizar sua moeda e retiram as preferências comerciais aos seus produtos. A indústria coreana, que já tinha alcançado patamar superior de desenvolvimento tecnológico, passa a transferir para o exterior, especialmente para os países asiáticos menos desenvolvidos (NIC de segunda geração ${ }^{6}$ e China), sua indústria manufatureira de bens intensivos em trabalho, concentrando-se cada vez mais nos setores intensivos em tecnologia e no setor de serviços (RIBEIRO e RUPPERT, 2011) 7 . Esse movimento de afluxo das inversões coreanas foi reforçado na década de 1990, quando a Coreia, seguindo o padrão de globalização mundial, promoveu maior liberalização econômica, comercial e financeira, permitindo maior entrada e saída de IDE.

Embora o governo tenha promovido reformas no sentido de liberalização de mercados, seguindo prescrição do FMI, o Estado estabeleceu rigorosos critérios de classificação de risco de crédito e exigiu reestruturação dos chaebols para que se tornassem mais transparentes e menos vulneráveis financeiramente. A lógica da financeirização

6 Malásia, Tailândia e Indonésia.

7 Esse modelo industrial de aprimoramento da qualidade de oferta do leste da Ásia ficou conhecido como o Paradigma dos Gansos Voadores (PALMA, 2004). 
na gestão das grandes corporações foi de certa forma limitada, "minimizando a fragilização econômica das grandes empresas e possibilitando maior sucesso na concorrência internacional" (RIBEIRO e RUPPERT, 2011, p. 102).

Empresas coreanas, como Samsung, LG e Hyundai, tornaram-se empresas multinacionais de grande destaque. Muitas firmas coreanas passaram rapidamente da condição de competidores apenas domésticos para importantes players globais. Para aumentar sua competitividade, a partir do final dos anos 1980 essas firmas dirigiram-se para o exterior em busca de expansão dos seus negócios, conhecimentos tecnológicos e, posteriormente, redução de custos de produção.

Primeiramente, as empresas coreanas investiram maciçamente em países desenvolvidos. Contudo, com o tempo, as decisões de localização do IDE modificaram-se e a Coreia passou a investir mais em países em desenvolvimento, concentradamente nos asiáticos. Os motivos que incitaram essas inversões diferem de acordo com o grau de desenvolvimento do país receptor. Diante de países desenvolvidos, seguindo a terminologia de Dunning (1997), as empresas coreanas apresentaram comportamento de market-seeking (orientado para a busca de mercados) e strategic asset-seeking (busca por ativos estratégicos, como tecnologia), buscando internalizar vantagens de propriedade do tipo transação. Alguns países em desenvolvimento também ofereceram seu grande mercado como fator atrativo ao IDE coreano - como a China e o Brasil -, entretanto a produção a baixo custo nessas economias e acesso a recursos naturais foram os principais fatores de atração das inversões externas coreanas (resource-seeking ou orientado para a busca de recursos) (MOON, 2007).

Moon (2007) argumenta que quatro fatores motivaram o IDE coreano, a saber: mão de obra barata, mercado doméstico saturado, desvantagens de custos e competição. Diversas firmas investiram externamente para ganhar eficiência e acesso a ativos de mercados estratégicos. As empresas coreanas que investiram em países asiáticos, por exemplo, foram em busca de mão de obra barata a fim de reduzir custos de produção e, nesse caso, a China foi a localidade preferida ${ }^{8}$. As empresas que destinaram seus recursos para a América do Norte e a Europa, em geral, foram em busca de mercados dos outros países (market-seeking) e de ativos estratégicos (strategic asset-seeking), com o objetivo de desenvolver tecnologia, pesquisa e desenvolvimento. Nos países desenvolvidos, o tipo de investimento externo foi predominantemente do tipo aquisição e fusão. De maneira geral, observa-se nos países em desenvolvimento um número maior de investimentos do tipo greenfield (DUNNING, 1997), entretanto o investimento ex8 Moon (2007) afirma que, de acordo com dados do Banco de Importação e Exportação Coreano (Korean
Eximbank), o trabalho na China, em 2004, custava um décimo do valor da mão de obra da Coreia. 
terno realizado pelas empresas coreanas concentrou-se também em fusões e aquisições, mesmo nas economias emergentes. Por fim, o IDE também foi utilizado pelas empresas coreanas como forma de driblar barreiras ao comércio e de se beneficiarem das quotas de comércio dos países receptores desses investimentos.

Muitas companhias procuraram mercados internacionais com o objetivo de pulverizar o risco de se investir apenas no mercado doméstico. Kim e Rhe (2009) ressaltam o papel dos mercados locais saturados e da acirrada competição industrial doméstica no processo de internacionalização das empresas coreanas - busca por sustentação dos lucros perdidos domesticamente. Além disso, os autores ressaltam que o IDE também foi utilizado como canal de desvio dos altos custos com a atividade exportadora dos produtos coreanos, devido aos custos de transação. O último fator determinante do IDE coreano, discutido por Moon (2007), foi a competitividade para que as empresas se tornassem marcas globais. Esta envolve a administração de questões trabalhistas, tentativas de alcançar seus competidores e localizações estratégicas das filiais. Em relação ao primeiro fator, empresas coreanas buscaram países onde tinham mais facilidade de administrar tensões entre os trabalhadores, como o Vietnã, por exemplo. Quanto ao alcance de seus rivais, algumas empresas coreanas investiram pesadamente no exterior para imitar ou compensar as vantagens adquiridas pelos seus rivais que iniciaram mais cedo o processo de internacionalização. Por fim, o destino estratégico do IDE coreano também revela a necessidade de as companhias estarem bem posicionadas nos mercados-chaves dos setores nos quais atuam.

Analisando-se os determinantes do IDE coreano, dentro do conceito do Investment Development Path (IDP) ${ }^{9}$, diversos autores argumentam que os padrões dessas inversões não são completamente explicáveis por essa teoria. Lee e Slater (2007) atentam para o fato de que o volume de IDE realizado pelo país atualmente - assim como diversas outras economias do leste asiático - alcança níveis que o IDP sugeriria para períodos futuros, ou seja, o IDP não consegue explicar totalmente o padrão de IDE realizado pela Coreia no atual estágio de desenvolvimento econômico que o país se encontra, pois a economia coreana se desenvolveu muito rapidamente, com grande destaque para a indústria manufatureira tradicional nos anos 1980 e para a manufatura eletrônica sofisticada nos anos 1990.

9 A teoria do Investment Development Path (IDP) postula a associação sistemática entre o nível de desenvolvimento econômico de um país e suas posições de entrada e saída de IDE. Nesse paradigma, um país passa por cinco estágios de desenvolvimento econômico, cada estágio caracterizado por padrões diferentes de entrada e saída de IDE. Espera-se que o investimento direto externo seja realizado nas etapas finais, quando o país já tiver acumulado quantidade significativa de vantagens de propriedade $(\mathrm{O})$ ou de localização específica (L) entre as firmas (DUNNING e NARULA, 2000; LEE e SLATER, 2007). 
Mathews (2006) afirma que a Coreia - e os demais NICs - pôde crescer tão rapidamente e ter seu papel dentro do sistema produtivo e comercial internacional aumentado tão significativamente ao longo das últimas duas décadas devido a três razões. Em primeiro lugar, a globalização permitiu que esses países tirassem proveito de novas oportunidades, às quais antes não tinham acesso, como mercados consumidores inexplorados, ligações entre firmas mais extensas e alavancagem de recursos facilitada. $\mathrm{O}$ segundo fator consiste no desenvolvimento de capacidades tecnológicas e ativos "criativos" por parte de algumas companhias coreanas. Isso fez com que suas participações no IDE total realizado por economias emergentes aumentassem. Por último, o autor ressalta que o próprio processo de globalização colaborou para que as EMNs dos países em desenvolvimento organizassem e integrassem de maneira efetiva seus negócios globais por meio de inovações estratégicas e organizacionais, fazendo com que essas empresas se destacassem no novo ambiente de negócios. Dessa forma, a Coreia seguiu seu próprio IDP em termos de política industrial governamental e os grandes conglomerados coreanos se internacionalizaram.

O processo de internacionalização dos grandes conglomerados coreanos foi liderado por empresas nacionais privadas (especialmente Samsung, LG e Hyundai), contudo contou não somente com o suporte do governo para o desenvolvimento das capacidades concorrenciais das empresas, mas também para a realização do próprio processo de internacionalização por meio de diversos instrumentos. Sem todo esse apoio, não seria possível a aceleração do processo de internacionalização de suas grandes empresas. Dunning e Narula (1996 e 2000) e Dunning, Hoesel e Narula (1997) explicitam teoricamente esse fato ao revisarem o IDP e introduzem a ideia de que a dinâmica de interação entre crescimento econômico, IDE e políticas públicas pode alterar a trajetória de desenvolvimento do investimento desse país, uma vez que o IDP de cada país é específico e dependente de trajetórias prévias.

Como mencionado, o papel do governo coreano foi essencial para o fortalecimento, a construção de capacitação competitiva e para a internacionalização das empresas nacionais. Na seção seguinte serão discutidos os principais instrumentos disponibilizados pelo governo coreano que incentivaram e facilitaram a realização do IDE pelas firmas coreanas.

\section{POLÍTICAS PÚBLICAS DE INCENTIVO AO IDE COREANO}

Lall (2004) ressalta que a criação deliberada dos grandes conglomerados privados coreanos foi um dos pilares da estratégia de desenvolvimento econômico e de transformação no tipo de inserção externa do país. Conforme Lall (2004, p. 19), 
Os chaebols foram empresas selecionadas dentre os exportadores de sucesso e aos quais foram dados diversos subsídios e privilégios, incluindo restrições à entrada de EMNs na Coreia, em troca da estratégia empresarial de criação de atividades intensivas em capital e tecnologia destinadas à exportação.

Essas empresas foram selecionadas pois, dada a deficiência de mercados de capital, habilidades, tecnologia e até mesmo infraestrutura, apenas grandes e diversificadas empresas poderiam assumir o risco e custos de internalizar atividades, absorver e, posteriormente, desenvolver tecnologia (sem um apoio substancial de IDE), criar filiais por toda a parte do mundo e estabelecer marcas globais com sua própria rede de distribuição. O governo coreano capacitou, ao longo das décadas de 1960 e 1970, empresas que se tornaram líderes em setores industriais de ponta já no final dos anos 1980.

Essa estratégia de alto risco e custo era administrada pela disciplina rígida imposta pelo governo coreano: "desempenho das exportações, competição doméstica vigorosa e intervenções deliberadas a fim de racionalizar a estrutura industrial" (LALL, 2004, p. 19) ${ }^{10}$. Em contrapartida, o governo também adotou diversas medidas para encorajar e garantir a possibilidade de criação e difusão de tecnologia como, por exemplo, a construção de maciça infraestrutura, qualificação dos trabalhadores com subsídios (e fornecimento público) à educação, treinamento e promoção de pesquisa e desenvolvimento de qualidade (CHANG, 2003).

Uma vez alcançado o objetivo de desenvolvimento de uma indústria forte e altamente competitiva no mercado doméstico e internacional, a internacionalização das empresas por meio do IDE foi vista como forma de fortalecer a competitividade industrial e também foi amplamente apoiada pelo governo. Por meio de diversas medidas, o governo coreano facilitou e promoveu o envio de investimento direto coreano para o exterior.

A discussão sobre os investimentos diretos externos feitos por empresas coreanas entrou na pauta governamental no final da década de 1960. Os poucos investidores que vislumbravam projetos internacionais encontravam pela frente um burocrático sistema regulatório para tal. Era necessária a aprovação no Ministério da Economia e Finanças, mediante apresentação de diversos documentos, como: contratos, permissões dos países hospedeiros, planejamento financeiro, entre outros (KIM e RHE, 2009; MOON, 2007).

Diante do crescimento apresentado pelos investimentos coreanos no exterior, o governo percebeu a necessidade de rever alguns aspectos do ambiente regulatório. $\mathrm{Na}$

\footnotetext{
${ }^{10}$ As empresas que não se enquadrassem no desempenho esperado tinham os recursos financeiros cortados, bem como os incentivos fiscais, o que inviabilizava a competição desta no mercado.
} 
segunda metade da década de 1970, o Ministério da Economia e Finanças executou transformações para garantir que as operações no exterior pudessem ser financiadas. Criou-se a necessidade de aprovação prévia dos projetos de investimentos internacionais pelo Banco da Coreia (Bank of Korea) para, depois, seguir com os demais procedimentos já existentes (KIM e RHE, 2009; MOON, 2007).

No começo da década de 1980, o governo coreano iniciou um processo de flexibilização do arcabouço regulatório referente aos investimentos no exterior, de forma a facilitar o processo de internacionalização das empresas coreanas. Não era mais necessária a pré-aprovação do projeto de internacionalização no Banco da Coreia ou a comprovação de competitividade no mercado doméstico, exigida anteriormente pelo Ministério. Em 1986, contando com superavit comercial e equilíbrio nas contas externas, o governo sul-coreano passou a encorajar as empresas ao processo de internacionalização. Outro fator que favoreceu o apoio ao movimento das empresas ao exterior foi o aumento do custo da mão de obra local, o que prejudicava o poder competitivo global das empresas coreanas (KIM e RHE, 2009; MOON, 2007).

A flexibilização regulatória aprofundou-se nos anos de 1990 e 2000 . Expandiu-se a permissão para investir externamente no mercado imobiliário, o que possibilitou as empresas a comprarem imóveis para alojarem seus trabalhadores e seguradoras a investir em imóveis no exterior. A permissão para investimentos no exterior também passou a ser concedida pelo Industrial Bank of Korea e pelo Korea Development Bank, além do Bank of Korea (Banco Central) e do Eximbank of Korea (Banco de Exportação e Importação da Coreia) (LEE, 2011). Após 2005, permitiu-se que empresas não financeiras investissem no exterior em atividades financeiras, bem como se passou a destinar mais recursos às empresas para financiar seus projetos de internacionalização por meio da canalização do excesso de divisas internacionais oriundas da conta corrente superavitária.

Do ponto de vista financeiro, dados do Eximbank of Korea mostram que houve substancial elevação da proporção dos desembolsos do banco para financiar projetos no exterior em relação ao IDE realizado coreano. Em 2000, esse indicador foi de apenas 1\%, já em 2005 a proporção subiu para 21\%, em 2010 para 23\%, 2013 para 33\% e, em 2016, para 45\% (Eximbank of Korea, vários anos).

Para obter sucesso no suporte e incentivo ao processo de internacionalização, o governo continuou com a flexibilização do aparato regulatório e criou novas formas de proteção e promoção aos investimentos externos. Os instrumentos de apoio à internacionalização oferecidos pelo governo coreano foram: financeiros, institucionais (fiscal e tributário), informativos e de segurança (Quadro 4). Para a implementação dessas políticas, o governo contou com algumas importantes instituições, a saber: Eximbank of Korea, Korea Export Insurance Corporation e International Management Institute. 


\section{Quadro 4 - Coreia do Sul: Instrumentos governamentais de incentivo à internacionalização das empresas coreanas}

\begin{tabular}{|c|c|c|}
\hline Instrumento & Agente & Descrição \\
\hline \multirow{2}{*}{ Financeiro } & $\begin{array}{l}\text { Export-Import Bank of } \\
\text { Korea }\end{array}$ & $\begin{array}{l}\text { Para reduzir encargos financeiros da empresa investidora, o banco } \\
\text { oferece empréstimos que podem cobrir até } 80 \% \text { dos investimentos } \\
\text { totais na atividade de internacionalização ( } 90 \% \text { para o caso de } \\
\text { pequenas e médias empresas). }\end{array}$ \\
\hline & $\begin{array}{l}\text { Economic Development } \\
\text { Cooperating Fund } \\
\text { (EDCF) }\end{array}$ & $\begin{array}{l}\text { Apoia investimentos em países em desenvolvimento, especialmente } \\
\text { para negócios que envolvam recursos de longo prazo ou que tenham } \\
\text { um longo período de recuperação do investimento. O empréstimo } \\
\text { pode ser pago em } 15 \text { anos com uma taxa de juros anual de } 5 \% \text { a } 6 \% \text {. }\end{array}$ \\
\hline \multirow{2}{*}{ Segurança } & Acordos de investimento & $\begin{array}{l}\text { Criados para proteger os investidores coreanos de possíveis riscos } \\
\text { provenientes do ambiente internacional (guerras, expropriações e } \\
\text { restrições às remessas monetárias). }\end{array}$ \\
\hline & $\begin{array}{c}\text { Sistemas de gestão } \\
\text { (Post Management System) }\end{array}$ & $\begin{array}{l}\text { O objetivo desse regulamento é induzir à gestão equilibrada no } \\
\text { exterior, prevenindo possíveis problemas causados nas subsidiárias } \\
\text { internacionalizadas e evitar fuga de capitais investidos. }\end{array}$ \\
\hline \multirow{3}{*}{ Institucional } & & Há algumas modalidades: \\
\hline & Isenção de Impostos & $\begin{array}{l}\text { i) Se um investidor paga imposto no país receptor, então o montante } \\
\text { pago será isentado dentro dos limites de isenção para aquele ano } \\
\text { fiscal; } \\
\text { ii) Se um país, que tiver acordo de tributação com a Coreia, optar por } \\
\text { isentar as empresas coreanas de alguns tributos, o mesmo } \\
\text { montante de impostos será isentado dessas firmas na Coreia. O } \\
\text { governo coreano reconhece esse benefício como imposto pago no } \\
\text { estrangeiro, de forma que a firma não tem de pagá-lo no país de } \\
\text { origem; } \\
\text { iii) Se um país detentor de certo recurso retirar a cobrança de } \\
\text { impostos sobre dividendos gerados com IDE coreano para o } \\
\text { desenvolvimento desses recursos, então o mesmo montante será } \\
\text { retirado na Coreia como forma de promoção do desenvolvimento } \\
\text { de recursos no exterior. }\end{array}$ \\
\hline & Acordos de Bitributação & Acordos efetuados em 62 países de modo a evitar a bitributação. \\
\hline \multirow{4}{*}{ Informativo } & $\begin{array}{l}\text { Korea Export Insurance } \\
\text { Company }\end{array}$ & $\begin{array}{l}\text { Agência de auxílio a empresas coreanas que passaram por perdas de } \\
\text { investimento referentes a quebras de contrato, risco de operação e } \\
\text { risco político. }\end{array}$ \\
\hline & $\begin{array}{c}\text { Korea Overseas Company } \\
\text { Assistance Center }\end{array}$ & $\begin{array}{l}\text { Agência do governo que coleta informações, presta serviços } \\
\text { administrativos, oferece suporte e resolve problemas referentes às } \\
\text { empresas coreanas no exterior. }\end{array}$ \\
\hline & $\begin{array}{c}\text { Rede de Informações sobre } \\
\text { IDE }\end{array}$ & $\begin{array}{l}\text { Com o objetivo de oferecer informações precisas para empresas } \\
\text { dispostas a iniciar o processo de internacionalização, o Ministério da } \\
\text { Economia e Finanças administra um site específico para promover os } \\
\text { investimentos no exterior. }\end{array}$ \\
\hline & $\begin{array}{l}\text { Korea Overseas Company } \\
\text { Information System }\end{array}$ & $\begin{array}{l}\text { Sistema administrado pelo Ministério da Economia e Finanças } \\
\text { (MOFE) no qual é possível encontrar na internet diversas informações } \\
\text { a respeito dos investimentos diretos no exterior, assim como } \\
\text { informações sobre as empresas coreanas internacionalizadas. }\end{array}$ \\
\hline
\end{tabular}

Fonte: Adaptado de Kim e Rhe (2009).

O Eximbank of Korea, criado na década de 1970 inicialmente para prover crédito às exportações, passou a financiar projetos de internacionalização no final da década de 1990. Os empréstimos feitos às empresas chegaram a até 90\% do capital investido 
no projeto de internacionalização. A Korea Export Insurance Corporation é uma agência do governo subordinada ao Ministério do Comércio, Indústria e Energia, responsável por oferecer seguros às empresas exportadoras coreanas contra a insolvência de eventuais compradores. A mesma agência oferece às empresas pertencentes ao movimento de internacionalização instrumentos de minimização de risco, como seguros contra guerras, expropriações, restrições de transferências e ruptura de contrato por parte do país hospedeiro do investimento (KIM e RHE, 2009).

São diversas as agências e ministérios que auxiliam na promoção da internacionalização das empresas coreanas. O Ministério da Economia e Finanças e o Eximbank utilizam-se da internet para alimentar sites contendo informações a respeito dos investimentos no exterior, procedimentos, características e países hospedeiros, enquanto que o International Management Institute, criado em 2005, auxilia pequenas e médias empresas, por meio de consultorias, a respeito de oportunidades no mercado internacional.

Além das agências e ministérios, o governo sul-coreano concentra esforços para aumentar o número de acordos bilaterais e de bitributação. Os acordos bilaterais envolvem mecanismos de proteção ao investimento em razão dos riscos proporcionados pelo país de destino do investimento. São previstos riscos como nacionalizações, expropriações, perdas geradas por guerras e revoluções. Também são garantidas as remessas de lucros e ganhos de capital. De acordo com os dados do Eximbank of Korea, esse acordo está presente em 62 países, e há negociações com outros países, entre eles o Brasil.

Os acordos de bitributação estão presentes em 57 países e em negociação com outros sete. Suas principais características são: (i) imposto sobre lucros devem ser tributados no país onde o negócio se realiza; (ii) rendimentos de bens imóveis devem ser tributados no país onde o imóvel se situa; (iii) juros e dividendos podem ser taxados em ambos os países, mas o país hospedeiro geralmente impõe uma taxa de $10 \%$ a 20\%; e (iv) eliminação da bitributação, ou seja, impostos pagos em um país devem ser deduzidos em outro.

Por meio desses diversos instrumentos e da administração regulatória sobre a entrada e saída de IDE, o governo coreano tem facilitado e incentivado a internacionalização das empresas nacionais, especialmente dos grandes conglomerados.

\section{CONCLUSÕES}

A industrialização coreana foi marcada pelo intenso intervencionismo do governo na economia. O Estado atuou, por meio de seus Planos Quinquenais de Desenvolvimento Econômico, de forma ativa na criação, desenvolvimento e consolidação de conjuntos de grandes empresas nacionais em cada setor considerado como estratégico. A escolha 
de mais de uma empresa nacional por setor foi essencial para que o plano nacional de desenvolvimento no setor não fosse inviabilizado, caso alguma empresa fosse malsucedida ou vendida a multinacionais em algum momento.

As políticas foram estabelecidas de forma racional, escolhendo as empresas que tinham maior capacidade organizacional, física, financeira, de inovação e de capital humano para empreender o projeto nacional de industrialização e concorrer em segmentos competitivos em âmbito internacional. As contrapartidas governamentais se deram tanto via acesso preferencial ao crédito internacional, isenções fiscais e proteção dos mercados domésticos dos setores escolhidos quanto por meio dos investimentos públicos em infraestrutura, educação, pesquisa e desenvolvimento.

A forma de ação do Estado certamente foi preponderante para o sucesso do desenvolvimento industrial coreano, inclusive com a internalização da Terceira Revolução Industrial - ao contrário do que ocorreu na América Latina, que não conseguiu sequer concluir sua Segunda Revolução Industrial. Contudo, a dinâmica regional asiática, com liderança do Japão, também exerceu papel crucial para que a Coreia conseguisse internalizar de forma exitosa a indústria pesada e, em um segundo momento, a indústria manufatureira sofisticada e de informação. Porém essa dinâmica não aconteceria se o Estado não tivesse promovido seu desenvolvimento industrial.

No âmbito da realização de IDE pelas empresas coreanas, a atuação do governo também foi essencial. Primeiramente por promover desenvolvimento industrial das empresas coreanas, fazendo com que fosse possível a concorrência em mercados internacionais. Em segundo lugar por promover diretamente o IDE coreano após os anos de 1980 e, mais intensamente, nos anos 1990, de forma que as ações entre os setores público e privado coreanos foram complementares, e não excludentes, ao longo das últimas décadas. Como resultado, o estoque do IDE coreano no exterior aumentou consideravelmente entre 1990 e 2015, com concentração em atividades industriais e de comércio. Do ponto de vista da distribuição geográfica, grande parte dos investimentos coreanos, desde 1990, dirigiu-se para a Ásia e para a América do Norte. Destaca-se atualmente a participação de China, Estados Unidos, Hong Kong e Vietnã como os principais países receptores do IDE coreano.

A despeito da internacionalização tardia, atualmente algumas empresas coreanas situam-se entre as 100 empresas transnacionais não financeiras com maior volume de ativos no exterior. Entre os fatores determinantes do investimento direto externo coreano, destacam-se, entre outros: mão de obra barata, mercado doméstico saturado, desvantagens de custos, concorrência e a nítida estratégia governamental em transformar a Coreia do Sul numa potência regional.

Nesse sentido, a internacionalização das empresas coreanas não foi resultado das forças livres de mercado. Houve o reconhecimento, por parte do governo coreano, da 
necessidade de seu apoio à inserção da Coreia do Sul nas estruturas produtivas e comerciais internacionais via IDE, uma vez que as empresas precisavam buscar formas mais competitivas de produção. Assim, foram estabelecidas políticas públicas coordenadas com o propósito deliberado de estimular a internacionalização das empresas. Estas compreenderam estratégias de expansão, que puderam ser observadas pela implementação dos diversos instrumentos postos à disposição do setor privado.

\section{REFERÊNCIAS}

AMSDEN, A. Country Study 14: Republic of Korea. Stabilization and Adjustments policies and programmes. Helsinki: UNU-WIDER, 1987.

CHANG, H-J. Chutando a escada: a estratégia do desenvolvimento em perspectiva histórica. São Paulo: Editora Unesp, 2003.

DUNNING, J. H.; NARULA, R. “The investment development path revisited: some emerging issues”. In: DUNNING, J. H.; NARULA, R. (Eds.). Foreign Direct Investment and Governments: Catalysts for Economic Restructuring. London: Routledge. 1996.

DUNNING, J. H.; NARULA, R. Industrial development, globalization and multinational enterprise: new realities for developing countries. Oxford Development Studies, n. 28, p. 141-167, 2000.

DUNNING, J. H.; HOESEL, R. V.; NARULA, R. Explaining the "new" wave of outward FDI from developing countries: the case of Taiwan and Korea. Research Memoranda 009. Maastricht: Maastricht Economic Research Institute on Innovation and Technology, 1997.

FUNG, K. C.; GARCIA-HERRERO, A.; SIU, A. A comparative empirical examination of outward foreign direct investment from four Asian economies: People's Republic of China; Japan; Republic of Korea; and Taipei, China. Asian Development Review, v. 26, n. 2, p. 86-101, 2009.

HYNIX SEMICONDUCTOR. Disponível em: <http://www.hynix.com>.

HYUNDAI. Disponível em: <http://www.hyundai.com>.

INFOMAG. Foreign Exchange reserves. [On-line] Informag, 2010. Disponível em: <http:// infomag.eucck.org/site/view/view.htm?num=9332>.

KIA MOTORS. Disponível em: <http://www.kiamotors.com>.

KIM, J. M.; RHE, D. K. Trends and determinants of South Korean Outward Foreign Direct Investment. The Copenhagen Journal of Asian Studies, Copenhagen Business School, v. 27, n. 1, p. 126-154, 2009.

KOREAN EXIMBANK. Disponível em: <http://www.koreaexim.go.kr/en2>.

KOREAN EXIMBANK. Annual reports. [On-line] Korean Eximbank, vários anos. Disponível em: <https://www.koreaexim.go.kr/site/program/board/basicboard/list?boardtypeid $=82 \&$ phototype $=$ list $\&$ menuid $=002001006004>$. 
LALL, S. Reinventing industrial strategy: the role of government policy in building industrial competitiveness, 2004, mimeo.

LEE, J.; SLATER, J. Dynamic capabilities, entrepreneurial rent-seeking and the investment development path: The case of Samsung. Journal of International Management, v. 13, n. 3, p. 241-257, 2007.

LEE, P. Investimentos coreanos no mundo: IED e internacionalização das empresas sul-coreanas. Dissertação (Mestrado em Geografia) - Departamento de Geografia, Universidade de São Paulo, São Paulo, 2011.

LG ELECTRONICS. Disponível em: <http://www.lg.com/global>.

MATHEWS, J. A. Dragon Multinationals: New Players in 21st Century Globalization. Asia Pacific Journal of Management, v. 23, p. 5-27, 2006.

MEDEIROS, C. A. "Globalização e a inserção internacional diferenciada da Ásia e da América Latina”. In: TAVARES, M. C.; FIORI, J. L. (Orgs.) Poder e dinheiro: uma economia política da globalização. Rio de Janeiro: Ed. Vozes, 1997.

MINISTRY OF KNOWLEDGE ECONOMY - KOREA. Disponível em: <http://www.mke. go.kr/language/eng/>.

MOON, H. C. "Outward Foreign Direct Investment by enterprises from the Republic of Korea”. In: UNCTAD. Global Players from Emerging Markets: strengthen enterprise competitiveness through outward investment. New York and Geneva: United Nations, 2007.

MOON, H. C.; YIN, W. The top 20 Korean multinationals: changes and continued growth of Foreign Investment. Emerging Markets Global Players Project - Korea. Seoul and New York: Columbia Center on Sustainable Investment / University of Columbia and Graduate School of International Studies / Seoul National University, 2015. Disponível em: <http://ccsi.columbia.edu/publications/emgp/>.

OECD - ORGANIZATION FOR ECONOMIC COOPERATION AND DEVELOPMENT. Disponível em: <http://www.oecd.org >.

PALMA, G. "Gansos voadores e patos vulneráveis: a diferença da liderança do Japão e dos Estados Unidos no desenvolvimento do sudeste asiático e da América Latina”. In: FIORI, J. L. (Org.). O Poder Americano. Petrópolis: Vozes, 2004.

RIBEIRO, E.; RUPPERT, L. “Coreia do Sul”. In: ACIOLY, L.; LIMA, L. A. F.; RIBEIRO, E. (Orgs.). Internacionalização de empresas. Experiências internacionais selecionadas. Brasília: IPEA, 2011.

SAMSUNG: Disponível em: <http://www.samsung.com/us>.

UNCTAD - CONFERÊNCIA DAS NAÇÕES UNIDAS SOBRE COMÉRCIO E DESENVOLVIMENTO. UNCTADStat. [On-line]. Disponível em: <http://unctadstat.unctad. $\operatorname{org} / \mathrm{EN}>$.

UNCTAD - CONFERÊNCIA DAS NAÇÕES UNIDAS SOBRE COMÉRCIO E DESENVOLVIMENTO. World Investment Report 1991: The Triad In Foreign Direct Investment. Genebra: ONU, 1991. 
UNCTAD - CONFERÊNCIA DAS NAÇÕES UNIDAS SOBRE COMÉRCIO E DESENVOLVIMENTO. World Investment Report 1992: Transnational Corporations as Engines of Growth. Genebra: ONU, 1992.

UNCTAD - CONFERÊNCIA DAS NAÇÕES UNIDAS SOBRE COMÉRCIO E DESENVOLVIMENTO. World Investment Report 1993: Transnational Corporations and Integrated International Production. Genebra: ONU, 1993.

UNCTAD - CONFERÊNCIA DAS NAÇÕES UNIDAS SOBRE COMÉRCIO E DESENVOLVIMENTO. World Investment Report 1994: Transnational Corporations, Employment and the Workplace. Genebra: ONU, 1994.

UNCTAD - CONFERÊNCIA DAS NAÇÕES UNIDAS SOBRE COMÉRCIO E DESENVOLVIMENTO. World Investment Report 1995: Transnational Corporations and Competitiveness. Genebra: ONU, 1995.

UNCTAD - CONFERÊNCIA DAS NAÇÕES UNIDAS SOBRE COMÉRCIO E DESENVOLVIMENTO. World Investment Report 1996: Investment, Trade and International Policy Agreements. Genebra: ONU, 1996.

UNCTAD - CONFERÊNCIA DAS NAÇÕES UNIDAS SOBRE COMÉRCIO E DESENVOLVIMENTO. World Investment Report 1997: Transnational Corporations, Market Structure and Competition Policy. Genebra: ONU, 1997.

UNCTAD - CONFERÊNCIA DAS NAÇÕES UNIDAS SOBRE COMÉRCIO E DESENVOLVIMENTO. World Investment Report 1998: Trends and Determinants. Genebra: ONU, 1998.

UNCTAD - CONFERÊNCIA DAS NAÇÕES UNIDAS SOBRE COMÉRCIO E DESENVOLVIMENTO. World Investment Report 1999: FDI and the Challenge of Development. Genebra: ONU, 1999.

UNCTAD - CONFERÊNCIA DAS NAÇÕES UNIDAS SOBRE COMÉRCIO E DESENVOLVIMENTO. World Investment Report 2000: Cross-border M \& A and Development. Genebra: ONU, 2000.

UNCTAD - CONFERÊNCIA DAS NAÇÕES UNIDAS SOBRE COMÉRCIO E DESENVOLVIMENTO. World Investment Report 2001: Promoting Linkages. Genebra: ONU, 2001.

UNCTAD - CONFERÊNCIA DAS NAÇÕES UNIDAS SOBRE COMÉRCIO E DESENVOLVIMENTO. World Investment Report 2002: Transnational Corporations and Export Competitiveness. Genebra: ONU, 2002.

UNCTAD - CONFERÊNCIA DAS NAÇÕES UNIDAS SOBRE COMÉRCIO E DESENVOLVIMENTO. World Investment Report 2003: FDI Policies for Development: National and International Perspectives. Genebra: ONU, 2003.

UNCTAD - CONFERÊNCIA DAS NAÇÕES UNIDAS SOBRE COMÉRCIO E DESENVOLVIMENTO. World Investment Report 2004: The Shift Towards Services. Genebra: ONU, 2004.

UNCTAD - CONFERÊNCIA DAS NAÇÕES UNIDAS SOBRE COMÉRCIO E DESENVOLVIMENTO. World Investment Report 2005: TNCs and the Internationalization of R\&D. Genebra: ONU, 2005. 
UNCTAD - CONFERÊNCIA DAS NAÇÕES UNIDAS SOBRE COMÉRCIO E DESENVOLVIMENTO. World Investment Report 2006: Transnacional Corporations and the Infrastructure Challenge. Genebra: ONU, 2006.

UNCTAD - CONFERÊNCIA DAS NAÇÕES UNIDAS SOBRE COMÉRCIO E DESENVOLVIMENTO. World Investment Report 2007: FDI from Developing and Transition Economies. Implications for Development. Genebra: ONU, 2007.

UNCTAD - CONFERÊNCIA DAS NAÇÕES UNIDAS SOBRE COMÉRCIO E DESENVOLVIMENTO. World Investment Report 2008: Transnational Corporations, Extractive Industries and Development. Genebra: ONU, 2008.

UNCTAD - CONFERÊNCIA DAS NAÇÕES UNIDAS SOBRE COMÉRCIO E DESENVOLVIMENTO. World Investment Report 2009: Transnational Corporations, Agriculture Production and Development. Genebra: ONU, 2009.

UNCTAD - CONFERÊNCIA DAS NAÇÕES UNIDAS SOBRE COMÉRCIO E DESENVOLVIMENTO. World Investment Report 2016: Investor Nationality: Policy Challenges. Genebra: ONU, 2016.

UNCTAD - CONFERÊNCIA DAS NAÇÕES UNIDAS SOBRE COMÉRCIO E DESENVOLVIMENTO. UNCTAD Statistics. [On-line] UNCTAD, 2017. Disponível em: $<$ http://unctad.org/en/Pages/statistics.aspx>.

YOON, D. R. Korea's Outward FDI in Asia: Characteristics and Prospects. In: ICRIER WORKSHOP ON INTRA-ASIAN FDI FLOWS, India, 2007. 